\title{
LOS PROCEDIMIENTOS DISCURSIVOS PARA LA CONSTRUCCIÓN MEDIÁTICA DE LA FIGURA DEL JOVEN POBRE Y DELINCUENTE. EL «CASO JONATHAN»
}

\author{
MARÍA FLORENCIA GENTILE*
}

\begin{abstract}
RESUMEN
El tratamiento de la noticia del asesinato de un gendarme en la entrada de un barrio pobre del conurbano bonaerense, se convirtió en una ocasión propicia para que los medios masivos de comunicación pongan en escena la figura mediática del joven (varón) de sectores populares asociado a la violencia y al delito. Figura estereotipada que aparece como natural y esencializada, esta construcción social condensa tres problemáticas diferentes entre sí: «inseguridad», «violencia en los jóvenes» y «delito», que constituyen fenómenos distintos, con causas diferentes y que requieren intervenciones particulares sobre cada uno de ellos. En este artículo se analiza la manera en que los medios (particularmente, los gráficos) trataron la noticia, para poner en evidencia ciertos procedimientos enunciativos presentes de forma recurrente en las narrativas en las que los jóvenes de sectores populares aparecen como cara indiscutible de la «inseguridad» y la violencia urbana, contrastando a su vez este tratamiento con los resultados de nuestro trabajo etnográfico en el mismo barrio. Reconstruir estos procedimientos permite desandar el camino de la naturalización para dar cuenta críticamente de uno de los mecanismos más importantes de construcción social del sentimiento de inseguridad y de sus consecuencias en el tratamiento de la cuestión juvenil.
\end{abstract}

PALABRAS CLAVE: ANÁLISIS DE DISCURSO, CONSTRUCCIÓN SOCIAL DE LA JUVENTUD, INSEGURIDAD

* Licenciada en sociología de la Universidad de Buenos Aires y máster en sociología de la École des Hautes Études en Sciences Sociales (EHSSParís). Actualmente realiza el doctorado de la Facultad de Ciencias Sociales de la Universidad de Buenos Aires. Investigadora/docente de la Universidad Nacional de General Sarmiento (UNGS) y becaria del CONICET. Correo electrónico: fgentile@ungs.edu.ar. 


\title{
OS PROCEDIMENTOS DISCURSIVOS PARA A CONSTRUÇÃO MIDIÁTICA DA FIGURA DO JOVEM POBRE E DELINQUENTE. $O$ «CASO JONATHAN"
}

\section{RESUMO}

O tratamento da notícia do assassinato de um policial militar na entrada de um bairro pobre dos arredores de Buenos Aires tornou-se oportunidade propícia para que os meios de comunicação de massa colocassem em cena a figura midiática do jovem (homem) de setores populares associado à violência e ao delito. Figura estereotipada que aparece como natural e essencializada, esta construção social condensa três problemáticas diferentes entre si: «insegurança», «violência dos jovens» e «delito», as quais constituem fenômenos distintos, com causas diferentes e que requerem intervenções particulares. Analisa-se neste artigo a forma pela qual os meios de comunicação (principalmente a mídia impressa) trataram a notícia, para evidenciar certos procedimentos enunciativos presentes de forma recorrente nas narrativas, nas quais os jovens de setores populares aparecem como retrato indiscutível da «insegurança» e da violência urbana. Contrastamos este tratamento com os resultados de nosso trabalho etnográfico no mesmo bairro. Reconstruir estes procedimentos permite desconstruir o caminho da naturalização para dar conta criticamente de um dos mecanismos mais importantes da construção social do sentimento de insegurança e de suas consequências no tratamento da questão juvenil.

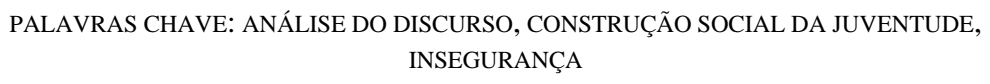

\section{DISCOURSE PROCEDURES ON THE MEDIA CONSTRUCTION OF THE POOR, YOUNG DELINQUENT. THE «CASE OF JOHNATHAN»}

\begin{abstract}
The way in which the news of the murder of a police official at the entrance of a poor district of the urban Buenos Aires, became a propitious occasion and the massive means of communication put in scene of the media figure of the young person (male) of an infamous sector associated to violence and crime. The stereotyped figure that appears natural and essensialized, so this social construction condenses three problematic areas with district differences: «insecurity», «violence in young people» and «crime», which constitute different phenomena, with different causes that require particular interventions according to each one of them. This article analyzes the way in which (particularly the graphs) were treated on the news, to put in evidence present declarative procedures of form certain appellant in the narratives in which the young people of infamous sectors appear as the unquestionable faces of «insecurity» and the urban violence, resisting treatment with the results of our ethnographic work in the same district. To reconstruct these procedures allows retraceable steps and the way of the naturalization to give a critical account of one of the most important mechanisms of social construction of the feelings of insecurity, and its consequences in the treatment of youth.
\end{abstract}

KEY WORDS: DISCOURSE ANALYSIS, SOCIAL CONSTRUCTION OF YOUTH, INSECURITY 


\section{INTRODUCCIÓN}

HACIA FINES DE OCTUBRE del 2008, un hecho interrumpió mi transcurrir cotidiano: la aparición de Jonathan en todas las radios, canales de televisión y medios gráficos. La imagen y las palabras de Jonathan, joven al que yo había entrevistado en varias oportunidades algunos años atrás durante una investigación ${ }^{1}$ en el barrio Ejército de los Antes (apodado como «Fuerte Apache»), ${ }^{2}$ eran insistentemente reproducidas en todos los medios de comunicación. Jonathan se había acercado a hablar con los periodistas que acudieron al barrio en ocasión de la muerte de uno de los gendarmes asignados a sus entradas por efecto de una bala que le impactó mientras estaba de guardia. Ante el aluvión de periodistas Jonathan se acercó rápidamente para contar con detalle, como lo había hecho en ocasiones anteriores conmigo pero esta vez frente a cámaras y micrófonos, la vida cotidiana en el barrio, las condiciones en las que viven los jóvenes y la relación que éstos mantienen con la policía y la gendarmería. Luego de 40 minutos en que los periodistas le realizaron todo tipo de preguntas, y también frente a las cámaras, la policía del barrio detuvo a Jonathan, de manera violenta, y

1 Entre fines del 2006 y mediados del 2007, participé de un equipo que llevó a cabo un trabajo etnográfico en este barrio, encargado por un conjunto de ministerios públicos del Gobierno de la Provincia de Buenos Aires, con el fin de relevar las condiciones de vida de sus habitantes. A su vez, estas indagaciones forman parte de mi propia investigación doctoral en curso acerca de los niños y jóvenes de sectores populares y su relación con las instituciones de inclusión social.

2 El Barrio Ejército de los Andes (apodado como Fuerte Apache, en alusión a la película estadounidense, por un periodista en los años 80) es un barrio ubicado en el Partido de Tres de Febrero, primer cordón del conurbano bonaerense. Delimitado por un complejo de viviendas públicas/monoblocks, construidos mayoritariamente durante los años 70 para reubicar parte de la población de una de las villas miserias más grandes de la Ciudad de Buenos Aires. Según los últimos datos oficiales, en él viven 3.299 familias (DPE, 2007). Asociado permanentemente a la realización de actividades delictivas, este barrio funciona como un elemento estigmatizante para sus habitantes, quienes (en especial los jóvenes) deben enfrentar diariamente el trato discriminador a partir de la sola mención de su lugar de residencia en sus interacciones cotidianas con personas de otros barrios, con las instituciones (en especial, las de control social como la policía), y como tratamos en este artículo, con los medios de comunicación. 
quedó arrestado en la comisaría durante 5 días. Los medios gráficos, de radio y televisión reprodujeron durante los días siguientes algunas de sus frases y las imágenes que Jonathan tenía filmadas en su celular, en las que aparecía manipulando un revólver. Al salir de la comisaría, Jonathan abandonó el barrio y no pudo volver nunca más.

\section{PROCEDIMIENTOS DISCURSIVOS PARA LA CONSTRUCCIÓN MEDIÁTICA DEL JOVEN POBRE Y DELINCUENTE}

El tratamiento de esta noticia se convirtió en una ocasión propicia para que los medios masivos de comunicación pusieran en escena la figura mediática del joven (varón) de sectores populares asociado a la violencia y al delito. Figura estereotipada que aparece como natural y esencializada. Esta construcción social condensa tres problemáticas diferentes entre sí: inseguridad, violencia en los jóvenes y delito, que constituyen fenómenos distintos, con causas diferentes y que requieren intervenciones particulares sobre cada uno de ellos. Analizar la manera en que los medios de comunicación trataron la noticia, nos permite poner en evidencia ciertos procedimientos enunciativos presentes de forma recurrente en las narrativas en las que los jóvenes de sectores populares aparecen como cara indiscutible de la inseguridad y la violencia urbana. Para ello nos dedicamos a recolectar y sistematizar las publicaciones gráficas y de portales virtuales de noticias, aparecidas a lo largo de una semana a partir del día del acontecimiento. ${ }^{4}$ Para el análisis utilizamos, a su vez, parte de los resultados de nuestro trabajo etnográfico en el mismo barrio, que resultan interesantes en su contraste con estas presentaciones mediáticas. Reconstruir estos procedimientos permite desandar el camino de la naturalización para dar cuenta críticamente de uno de los mecanismos más importantes de construcción social del sentimiento de inseguridad, y de sus consecuencias en el tratamiento de la cuestión juvenil. ${ }^{5}$

$4 \quad$ El hecho ocurrió el 29 de octubre de 2008.

5 Resulta relativamente reciente en la Argentina la estructuración del estereotipo del joven pobre y delincuente como figura de lo amenazante. Tal como lo explican Kaminsky, Kessler y Kosovsky en sus estudios sobre el sentimiento de inseguridad frente al delito, esta figura se constituye durante la década del noventa como un eje estable de las imágenes mediáticas de la «inseguridad». El otro eje que se estructura en esa década es el de los «delitos novedosos» («motochorros», «secuestros express», etcétera) que 


\section{DESCONTEXTUALIZACIÓN Y RECONTEXTUALIZACIÓN DEL «CASO». LA CONSTRUCCIÓN DE SERIES}

El asesinato del gendarme en el barrio «Fuerte Apache» irrumpió repentinamente en todos los medios de comunicación con la lógica de la novedad, propia del relato de un hecho como «noticia». Los canales, las radios y los periódicos competían en la presentación y despliegue de todos los detalles respecto de la «mecánica» del crimen: cómo había muerto el gendarme, dónde estaba ubicado cuando sufrió el impacto de la bala, desde dónde se suponía que ésta había venido. La multiplicidad de detalles del crimen contrastaba con una ausencia de explicación sobre el contexto en el que éste había ocurrido: esta muerte aparecía como un suceso aislado de todo proceso o contexto sociocultural. De esta manera, la manifestación de la violencia que implica el hecho no aparece como consecuencia de ningún tipo de relaciones que le otorguen sentido y ayuden a comprender su aparición, sino como causa, expresión de la simple maldad de quien la ejerce, de manera irracional e inexplicable. Esta manera de aparición responde al recurso narrativo de la «exasperación de un caso», permanentemente utilizado como forma de representación de la violencia en los medios de comunicación, con el fin de lograr romper la receptividad, a fin de atraer una mayor atención de las audiencias (Urresti, 2008). «Dada la lógica fragmentaria de esta presentación, el caso no remite nunca a contextos más amplios de argumentación y explicación: se cierra sobre sí mismo, agotando en la pura narración del hecho toda la exposición y el conocimiento posible». (Alabarces, Coelho, et al., 2000:212).

Sin embargo, la descontextualización social y cultural que aparece en el relato del hecho se compensa con otras formas de recontextualización propuestas. Por una parte, a través del tratamiento del «caso» como una manifestación particular de una situación de inseguridad

se presentan como «olas». Ambos se distinguen de las figuras de lo amenazante percibidas durante la transición democrática, ligadas a la herencia de la última dictadura militar (la «mano de obra desocupada» vinculada a bandas delictivas). Así, los investigadores dan cuenta de cómo las figuras de lo amenazante son construcciones históricas que van cambiando a lo largo del tiempo, y la manera en que aparecen en los medios contribuye a configurar una estructura de sentimientos determinada vinculada a lo que, en cada momento, se entiende y percibe como «inseguridad». Ver Kaminsky, Kessler, Kosovsky, 2007:83. 
que se presenta como constante y permanente, y que entonces aparece confirmada por la aparición cada nuevo caso (Kaminsky, Kessler, Kosovsky, 2007:81). Por otro lado, al relacionar el hecho con otros «casos» ocurridos, lo inscribe de esta manera en una serie temática determinada. En la noticia que nos ocupa, su tratamiento la inscribió dentro de una serie particular: delitos cometidos por niños y jóvenes provenientes de sectores populares, tratados generalmente con el apelativo de menores. En algunos medios esta relación se realizó de manera indirecta, y en otros se hizo explícita: Infobae concluye el relato sobre la noticia: «Así, se muestra una vez más la situación de violencia y de relación con el delito en la que viven los adolescentes en la provincia de Buenos Aires, mientras se agita el debate por una eventual reforma del sistema penal juvenil bonaerense» (Infobae, reproducido el 29 de octubre de 2008).

Lo interesante de este caso es que nada en el hecho mismo hacía suponer la participación de un joven, ni mucho menos su autoría. Los medios llegan a establecer esta relación a través de la aparición de Jonathan frente a las cámaras, y su manifestación de que el supuesto autor fue «un pibito». Durante los días siguientes, se reprodujeron y repitieron insistentemente $^{6}$ las declaraciones de Jonathan en las que decía:

Vino un pibito de laburar, que capaz que se habrá ido a las seis o siete de la mañana a meterse a una casa. Vio a los gendarmes que estaban 'pestañeando’ y le tiró un tiro (Reproducido el 29 de octubre de 2008 en La Nación.com; Infobae.com; blog del Canal 26 Noticias; Diario La Prensa; el 30 de octubre de 2008 en La Nación; Página12; Clarín.com; Infobae.com).

Yo creo que esto lo hizo un pibito por pura diversión.

(Reproducido el 30 de octubre de 2008 en La Nación; Página12; Clarín.com; Infobae.com; el 31 de octubre de 2008 en Página12).

Así, este caso fue rápidamente asociado a otro ocurrido días antes: el asesinato del ingeniero Barrenechea en San Isidro, que también había sido adjudicado por la policía y los medios de comunicación a un grupo de jóvenes entre los que se encontraban menores de edad, cuestión que finalmente nunca fue confirmada.

6 Vale la pena subrayar el hecho de la repetición exacta de las mismas frases en distintos medios de comunicación. No es necesario ahondar acerca del efecto que esta repetición tiene en la fijación de los sentidos asociados con la noticia en cuestión. 
Esta manera de presentación del caso como integrante de una «serie» genera como efecto — como señalan otras investigaciones sobre el tema (Arfuch, 1995) — la idea de un progresivo y constante aumento de este tipo de hechos, que no necesariamente guardan relación con un aumento efectivo o en una proporción equivalente a la de su tratamiento mediático. Ello contribuye a la constitución del tema de los delitos cometidos por jóvenes y/o menores en términos de alarma social, haciéndose eco al mismo tiempo que propiciando, la demanda de respuestas sociales y políticas con carácter de urgentes y drásticas. ${ }^{7}$

\section{EL CARÁCTER «JUVENIL» DEL HECHO}

¿Por qué se le atribuyó tanta importancia a una pequeña expresión de un supuesto testigo dentro de un reportaje de cuarenta minutos de duración? Es que las frases de Jonathan permitieron a los medios construir una narrativa en donde las características que se resaltaban del hecho coincidían con aquéllas atribuidas al delito juvenil. Como por ejemplo, su carácter irracional y gratuito, y su relación con la existencia de «bandas». De allí la insistencia en repetir las siguientes declaraciones, de las que salieron los extractos que a su vez se utilizaron como titulares durante los días siguientes:

Yo creo que esto lo hizo un pibito por pura diversión. Se escucharon los disparos, pero nadie sabe nada. Yo creo que el que lo hizo fue para tener fama, para entrar a un determinado grupo que hay dentro del barrio que le decimos 'La Isla'. Hay entre cincuenta o sesenta bandas de pibes que se portan mal. Para entrar tenés que robar y hasta matar (Página12, 30 de octubre de 2008).

7 En el contexto que presentamos, la «serie» puesta en escena en esos días se completó con la sucesión de ciertas reacciones sociales, también con mucha presencia mediática. Por un lado, las manifestaciones y marchas realizadas por los vecinos de las zonas ricas del Gran Buenos Aires que asociaban la «seguridad» con medidas de endurecimiento penal. Por otro lado, la presentación del proyecto de ley impulsado por el gobernador de la Provincia de Buenos Aires para bajar la edad de imputabilidad penal, intento de reforma que volvió a resurgir en el momento de escribir este artículo, a raíz de la presentación de nuevos «casos» de la serie. 
Y a partir de esa frase, los titulares:

Asesinan a un gendarme y creen que fue «por diversión» (Clarín, 30 de octubre de 2008).

Joven dijo que el crimen del gendarme fue «por diversión» (Blog del Canal 26 Noticias, 29 de octubre de 2008).

Fuerte Apache: después del asesinato del gendarme, adolescentes denuncian que hay 'unas ochenta bandas' en el barrio (Blog de Radio Continental, 590 AM, 29 de octubre de 2008).

El asesino de Fuerte Apache que mató «por diversión» a un gendarme sigue prófugo (Infobae.com, 30 de octubre de 2008).

Resaltar que la diversión fue el móvil de un hecho criminal de la gravedad de un asesinato lleva a configurar y acentuar la idea de la irresponsabilidad e irracionalidad ${ }^{8}$ de quien lo comete, atributos que a su vez se adjudican a la identidad del ser joven. «Ser joven será entonces equivalente a sujeto en formación, en transición, aún no dueño de reacciones y emociones, débil, indeciso, inexperto, presa fácil de tentaciones y flaquezas, de moralidad incierta, que necesita tutoría y orientación» (Arfuch, 1997:12). Lo mismo ocurre con el vínculo que se establece entre el asesinato y la existencia de bandas en el barrio: más allá de la existencia o no de estas bandas, nada en la reconstrucción de los hechos conduce a algún tipo de vínculo con ellas. Su mención como parte de la construcción del caso resalta nuevamente su carácter juvenil, en tanto éstas constituyen la forma de sociabilidad juvenil por excelencia. Así, en un movimiento enunciativo circular, la descripción de los hechos y el supuesto autor se van configurando mutuamente, de tal manera en que la sola descripción de las características del crimen parece contener los elementos indicativos de quién fue el autor (un joven), y al mismo tiempo, construye a ese autor (el joven) como alguien capaz de cometer delitos con esas características.

8 En relación con la idea de irresponsabilidad e irracionalidad del crimen cometido, los medios retomaron las declaraciones del director de Gendarmería: «El director general de Gendarmería, Héctor Schenone, opinó que lo ocurrido 'no tiene explicación desde el punto de vista lógico. Parece la acción de un loco o de un loco cobarde'». Página12 y Clarín.com, 30 de octubre de 2008. Y también: «La agresión que recibió Centeno fue salvaje y sin sentido», La Nación, 30 de octubre de 2008. 
De esta manera, la construcción del carácter juvenil de un hecho delictivo llega a constituirse incluso con independencia de la edad de quien lo comete. Como afirma Leticia Sabsay «si la guerra de pandillas es un fenómeno definido como juvenil, está claro que todos los sujetos involucrados en hechos de este género pertenecerán a este grupo 'etario' independientemente de la edad que tengan» ${ }^{9}$ (Sabsay, 1997:64).

\section{5. «LOS PIBES»: LA CONSTRUCCIÓN SOCIAL DE LAS CATEGORÍAS DE EDAD}

Sin embargo, el uso que Jonathan realiza de la categoría pibito no puede ser tomado unívocamente como una referencia directa a la edad de la persona que cometió el crimen (equivalente a menor de dieciocho años). Por el contrario, detenernos un momento en el uso que Jonathan da a la categoría "pibito» nos permite reflexionar sobre la construcción relacional de las categorías de edad, y los distintos significados y clasificaciones que operan en los distintos grupos sociales.

En un recuadro que acompañaba la descripción de los hechos en Clarín del 30 de octubre de 2008, se reprodujeron varias frases textuales del relato de Jonathan (esta vez, no incorporadas a una nota redactada por los periodistas), que nos permiten entrever los usos que Jonathan realiza de esta categoría:

Los pibitos que salen a robar son cada vez más chiquitos.

Los pibes como yo ahora pensamos en trabajar y hacer una vida nueva y los que no cambian piensan en hacer algo mucho más grande que matar a un gendarme. ${ }^{10}$

El conocimiento de la historia de Jonathan y del contexto social y cultural en que fueron producidas estas frases nos llevaron a identificar en ellas una distinción que podría pasar inadvertida para otros lectores. ${ }^{11}$ En estas

9 Las cursivas son nuestras.

10 Las cursivas son nuestras.

11 Alejandro Isla explica que comprender un lenguaje y lograr el aprendizaje de una cultura «no solamente implica el conocimiento del significado de palabras o términos en su traducción original a otra lengua, sino que demanda el conocimiento de los matices de significación en relación con el objeto o la situación. Matices que pueden ser introducidos por un tono, un acento, un silencio, un gesto, o la variación de significado que produce el uso de un término en un contexto particular» (Isla, 2002:297). 
frases Jonathan está estableciendo una clasificación que distingue a los pibitos de «los pibes como yo», entre los que a su vez establece una jerarquía. Es así que cuando dice que la muerte del gendarme fue cometida por un pibito por diversión, está diferenciando este accionar del tipo de acciones que pueden cometer «un pibe como yo», categoría que incluye, como lo explica a continuación, a quienes ya no delinquen («piensan en hacer una vida nueva»), o si lo hacen, se arriesgan a cometer delitos más rentables («algo mucho más grande que matar a un gendarme»). Esta frase, pasada por alto en los subrayados de los medios, da cuenta de que la categoría de pibito es utilizada por Jonathan para dar cuenta de una posición social determinada (de la que intenta distinguirse), de un estatus social de menor relación jerárquica que «los pibes como yo». La posición social a la que refiere el término pibito no guarda entonces una relación inmediata o lineal con la edad de la persona, sino que utiliza como criterio de distinción la experiencia recorrida, el tipo de delitos o infracciones que se cometen y los criterios morales de quienes comenten estas acciones.

Esta distinción no es exclusiva de Jonathan. Por el contrario, la categoría de «los pibes» es una categoría tradicionalmente presente en la cultura popular argentina, pero que, desde mediados de los años noventa adquiere una nueva significación. Se utiliza para designar a los pibes chorros, en referencia a las nuevas generaciones que tienen una relación diferente a la que tuvieron las anteriores tanto con el mercado de trabajo como con el delito.

Las investigaciones que dan cuenta de la subcultura tradicional delictiva en la Argentina - la de los chorros viejos_, muestran que ésta compartía algunos de sus rasgos con la «cultura del trabajo», propia de un contexto histórico de estabilidad y expansión del mercado de trabajo y de mecanismos estatales de integración social. Se señala así que esta cultura delictiva se trataba de un mundo con una fuerte estructuración normativa, en donde robar constituía una actividad que podía articular una «carrera profesional» delictiva, con etapas y ascenso en la jerarquía; y las prácticas se regían por la existencia de importantes criterios morales y profesionales - como por ejemplo, en la elección de la víctima (Miguez, 2002)—— ${ }^{12}$ que tenían como resultado

12 Daniel Miguez hace referencia a las investigaciones de Isla para describir los códigos clásicos de la subcultura delincuente, al mencionar que la victimización es regulada por un sistema normativo interno que indica, por ejemplo, que no se deben escoger como víctimas a personas carentes, y esto por dos motivos. Por un lado, por un criterio de ética o so- 
la regulación del uso de la violencia en los actos delictivos y en la relación con la policía (Isla, 2002).

Sin embargo, tanto la cultura del trabajo como la subcultura del delito sufrieron importantes transformaciones en las últimas décadas, en relación con la desarticulación del mercado de trabajo en la Argentina y sus consecuencias en la estructura social. Dichas transformaciones se ponen de manifiesto en las significaciones y prácticas de los jóvenes de sectores populares en su vinculación con el trabajo y con el delito (Kessler, 2004), ${ }^{13}$ y que aparecen de modo paradigmático en los valores y las prácticas de los autodenominados pibes chorros. Esta designación identifica a los jóvenes que realizan actividades ilegales pero que no se dedican a ellas necesariamente de manera exclusiva ni prioritariamente sin

lidaridad social, ya que la otra persona se encuentra en una situación de debilidad mayor o igual que el que realiza el delito. Por otro lado, por un criterio de eficiencia profesional: el botín que se puede obtener es más pequeño. Ver Miguez, 2002:325.

13 Gabriel Kessler subraya la importancia de las transformaciones estructurales que llevaron a una experiencia inédita en la Argentina: la existencia de segundas o terceras generaciones de familias con inserción precaria e inestable en el mercado de trabajo. Las nuevas generaciones fueron naturalizando progresivamente la inestabilidad del empleo, y lejos de concebir la posibilidad de una «carrera profesional», el futuro se les presenta como un horizonte de precariedad duradera: «imaginan -en el mejor de los casosuna sucesión de puestos de baja calificación y magros ingresos, todos inestables, interrumpidos por períodos de desempleo» (Kessler, 2002:342). Es así como en estos jóvenes se opera el pasaje de la «lógica del trabajador» a la «lógica del proveedor» como criterio para la acción. Mientras que en la primera, la fuente de legitimidad de los recursos obtenidos reside en el origen del dinero, es decir, que sea el fruto de un trabajo «digno» y reconocido socialmente; en la «lógica del proveedor» la legitimidad está puesta en el tipo de utilización que se hace del dinero; es decir, el hecho de usarlo para satisfacer necesidades. Este cambio trae como consecuencia a su vez un desdibujamiento de la distinción entre legalidad o ilegalidad en la acción que provee tales recursos. Actividades legales e ilegales se articulan de forma equivalente en estrategias para la obtención de recursos y dejan así de concebirse como excluyentes: «si la inestabilidad laboral dificulta imaginar alguna movilidad ascendente futura, en el presente lleva a que el trabajo se transforme en un recurso de obtención de ingresos más entre otros, junto con pedido en la vía pública, el 'apriete’, el 'peaje' y el robo, pudiendo recurrir a unos o a otros según la oportunidad y el momento» (Kessler, 2002:343). 
llegar a desarrollar una carrera delictiva, sino que tienen una relación intermitente tanto con el delito como con el mercado laboral. Se distinguen de los chorros tradicionales por un lado, por el tipo de actividades que realizan, que implican no sólo robos sino otro tipo de actividades ilegales como la prostitución masculina, el tráfico de drogas a microescala, el apriete, cobrar peaje, ${ }^{14}$ etcétera (Miguez, 2002:329). Actividades todas que requieren escasa planificación, baja calificación y magras y discontinuas ganancias, características que comparten con aquellas actividades a las que pueden acceder en el mercado de trabajo (Kessler, 2002:347). Por otra parte, la diferencia con los viejos chorros radica en los criterios normativos que organizan las acciones delictivas: no operan los antiguos criterios de victimización y la elección de la víctima se relaciona más con la improvisación en relación con la oportunidad del momento; y sobre todo, un cambio en la regulación del uso de violencia en los actos delictivos, que aparece como un aumento de su uso - tanto frente a las víctimas de delitos como en los enfrentamientos con la policía-, y es visto por los demás como una violencia irracional (Miguez, 2002) (Kessler, 2002). Temas sobre los volveremos más adelante.

Así, la categoría de pibes chorros pone de manifiesto un conflicto y contradicción entre estas nuevas formas de comprensión de la realidad y las formas tradicionales (tanto las relacionadas con la cultura del trabajo como aquéllas propias de la subcultura delictiva). Lo que me interesa resaltar es que, si bien estas distintas formas de comprensión de la realidad se expresan como un conflicto generacional, con el paso del tiempo estas representaciones y prácticas van cobrando cierta independencia de la edad de sus portadores; es decir, ya no son sólo los más jóvenes quienes adscriben a la lógica de los pibes chorros. En las entrevistas que mantuve con Jonathan, él identificaba como pibes grandes a aquellas personas que se manejaban con algunas de las formas de comprensión de la realidad propia de los pibes chorros pero que tenían alrededor de cuarenta años. Jonathan diferenciaba a su vez a estos pibes grandes de los antiguos, que identificaba con las formas de comprensión tradicionales de la subcultura delictiva. ${ }^{15}$

14 Se refiere a la práctica de pedir algún tipo de retribución monetaria para permitir la circulación por un territorio determinado.

15 Sergio Tonkonoff explica en relación con esto que en los sectores populares, históricamente, el pasaje a la madurez se realizaba más rápidamente que en los sectores medios, cobrando centralidad la actividad laboral sostenida y la formación de una familia propia. Pero las transfor- 
Es en este contexto que es necesario comprender las declaraciones de Jonathan, y su imputación de que el crimen del gendarme fue realizado por «un pibito» y «por diversión». El acento de Jonathan está puesto en que se trata de una acción que coincide con el accionar propio de los pibes chorros, de la que en este caso él quiere diferenciarse. ${ }^{16}$ Resalta el carácter de no planificado «No creo que haya sido una muerte premeditada, me parece que fue ocasional», dijo Jonathan el 29 de octubre de 2008 entrevista que se reproduce en el Blog de Radio Sudamericana 100.5. Sus declaraciones se comprenden más en relación con la oportunidad que con la lógica del costo-beneficio «Vino de laburar [...], vio a los gendarmes que estaban 'pestañando' y le tiró un tiro», destacando un uso de la violencia que se separa de los códigos tradicionales y una relación diferente con las fuerzas de seguridad.

Sin embargo, desconociendo estos significados y clasificaciones presentes actualmente en el mundo popular, en los medios de comunicación tomaron las palabras de Jonathan como un testimonio inequívoco de la participación de un menor de edad en el asesinato del gendarme, lo que premitió presentarlo rápidamente como un caso más de la serie de delitos cometidos por jóvenes o menores.

\section{INVERSIÓN VERIDICTIVA Y PASAJE DE LA FIGURA DE TESTIGO A LA DE VICTIMARIO}

Sería un joven de 18 años el asesino del gendarme. Sería de apellido Luque y viviría a pocos metros de la garita donde se produjo el asesina-

maciones estructurales operadas durante los noventa llevaron a una transformación en estas formas tradicionales de socialización, y actualmente fuera o en los márgenes del mercado laboral, y más lejos aún de la educación formal, muchos miembros de estos sectores no tienen más remedio que ser «socialmente jóvenes» (Tonkonoff, 2007:156-157).

16 Aunque durante las entrevistas que le realizamos hace dos años, él se identificaba como «pibe chorro». Quizás en este caso esté operando, además de un intento por presentarse frente a las cámaras con un estatus de mayor jerarquía, el hecho de que, en el momento del acontecimiento que nos ocupa, Jonathan hacía dos semanas que había cumplido dieciocho años. Esta edad es reconocida por los jóvenes en conflicto con la ley como un cambio en su estatus jurídico, pasando a ser considerados «mayores de edad» y por lo tanto, sin atenuantes en el tratamiento y los castigos previstos penalmente. Quizás esto estuviera incidiendo en su intento de percibirse y presentarse como «un pibe más grande» que se diferencia de los «pibitos». 
to. El presunto autor del disparo que mató a Centeno vive en el departamento $\mathrm{N}^{\circ} 412$ de la tira 24 del barrio Ejército de Los Andes, a metros de la garita donde fue asesinado el suboficial Centeno» (Infobae.com, 31 de octubre de 2008).

A la inversa de la lógica judicial — cuando se trata de jóvenes y delitos- el relato mediático generalmente parte de la certeza de la inculpación, aún sin basarse necesariamente en alguna prueba, para pasar con el correr del tiempo a la presunción, e incluso a veces, a la desmentida, que nunca ocupará la dimensión editorial de la inculpación. Este mecanismo es mencionado por Arfuch como inversión veridictiva y es recurrente en la construcción de las noticias relacionadas con niños y/o jóvenes y delitos. Más allá de las discusiones acerca de la ética periodística, interesa señalar que este mecanismo genera efectos específicos en la audiencia: «Este procedimiento no es para nada inocente [...]. La atribución de culpabilidad, que va de 'menores' a 'jóvenes' o 'un chico' y que terminará diluyéndose como noticia falsa, deja sin embargo una impresión (visual, gráfica) que difícilmente se borra para el lector apresurado: quizá lo que perdure sea sólo ese horror reiterado del crimen juvenil» (Arfuch, 1997:26).

Por otro lado, esta inculpación inmediata lleva a veces a publicar sin mediaciones datos personales del supuesto autor del hecho, sin reparar en los efectos que esta exposición puede tener para la vida de los jóvenes o niños involucrados.

Pero en el caso que nos ocupa, esta inversión enunciativa tuvo una característica particular y aún más sorprendente: en un mismo movimiento, convirtió al propio testigo del hecho (Jonathan), en equivalente/representante del victimario. ¿Cómo se operó este pasaje en la narración de la noticia?

Si los relatos de testigos son generalmente presentados en la crónica policial como la voz de la gente que recrea los valores sociales hegemónicos diferenciándose de la figura del victimario y acercándose a la de la víctima, en este caso los relatos de Jonathan cumplieron un rol diferente. Jonathan fue representado por los medios como prototipo de lo que se supone que es un joven habitante del «Fuerte Apache», mostrando una imagen de familiaridad con actividades ilegales como el acceso a las armas, al consumo de drogas y al crimen, en una operación que en un mismo acto estigmatiza a los jóvenes y al propio barrio como peligroso y responsable de la inseguridad. Por asimilación, Jonathan fue mostrado entonces como una especie de equivalente del supuesto 
autor del asesinato, operándose un interesante pasaje de la figura del testigo a la del victimario. Para sostener el efecto de veracidad de este desplazamiento narrativo, los medios extractaron de la extensa entrevista sólo algunas frases, en las que él mismo utilizaba, como recurso discursivo, la apelación a la primera persona para explicar los posibles móviles del hecho (por ejemplo: «A mí, careta, también me da para pegarle un tiro a un gendarme porque me cagaron a piñas mil veces»). ${ }^{17}$

Los efectos de este tratamiento no se hicieron esperar: Jonathan fue el primer detenido en el caso del asesinato del gendarme, violentamente arrestado frente a las cámaras, en una escena mediática que involucró la actuación de la propia policía representando una imagen de eficiencia y respuesta inmediata frente a los hechos que sacuden a la opinión pública, sin ninguna otra justificación que la figura jurídica (siempre arbitraria) de resistencia a la autoridad por parte de Jonathan.

Así, de ser el testigo que relata las circunstancias del acontecimiento que dio origen a la cobertura mediática, Jonathan pasó a convertirse en la propia noticia. En los distintos medios se empezó entonces a tratar su caso, analizar sus frases, exponer su vida. Incluso la

17 Frase reproducida el 29 de octubre en el blog de Radio Sudamericana y en el blog de El Bonaerense, y en Clarín, el 30 de octubre. La Nación, 30 de octubre: «Los agentes pretendieron identificarlo y el joven se resistió, por lo que fue demorado y se le secuestró su teléfono celular, en el cual se hallaron videos grabados con imágenes de él cuando empuñaba un revólver». Canal 26: «el joven que fue interceptado por la policía, que pretendió identificarlo para que fuera a declarar como testigo. Pero como se resistió al procedimiento, los efectivos terminaron por demorarlo, introducirlo por la fuerza en una patrulla y llevarlo a una dependencia policial. Fuentes judiciales informaron que el joven quedó detenido por resistencia a la autoridad a disposición del fiscal de San Martín, Rubén Moreno, quien secuestró en su poder un teléfono celular en el que había imágenes de jóvenes armados. Los voceros explicaron, que entre las imágenes hay videos del propio dueño del teléfono con un arma en su mano». Infobae, 29 de octubre: «Ante semejante revelación, el personal policial decidió aprehenderlo para determinar la veracidad de sus palabras. Sin embargo, el joven ya había advertido: 'Nunca van a encontrar a los que hicieron esto por la ley del barrio'. Sin embargo, a los pocos minutos de su testimonio y de la detención, los vecinos del barrio Ejército de los Andes, tristemente conocido como Fuerte Apache, se acercaron al móvil de C5N y entregaron las imágenes tomadas con un teléfono celular, en la que se ve al mismo muchacho con un enorme revólver en su poder». El mismo párrafo es reproducido en La Prensa (Las cursivas son nuestras). 
manera en que fue tratado el arresto que Jonathan sufrió frente a (y por la presencia de) las cámaras, continuaba con la equiparación entre Jonathan y el autor del crimen, justificando su detención como una forma de sanción a sus dichos.

Jonathan es un joven de «Fuerte Apache», quien luego de las declaraciones a los medios fue detenido, ya que dijo que «el crimen seguramente se cometió por diversión» (Blog de Radio Sudamericana, 100.5, 29 de octubre de 2008).

El descubrimiento a posteriori de su detención, de un video grabado en su propio teléfono móvil en el que Jonathan aparecía con un arma en la mano, fue difundido en medios gráficos y televisivos, y presentado como una manera de justificar el deslizamiento culpabilizador de la figura de testigo a la de victimario.

\section{CONSTRUCCIÓN DEL VICTIMARIO COMO UN EXTRANJERO SOCIAL Y LOS DISTINTOS SIGNIFICADOS SOCIALES DE LA VIOLENCIA}

Habilitada por este desplazamiento, la presentación de Jonathan en los medios siguió los mismos mecanismos discursivos que se ponen en práctica al presentar al sospechado autor de un hecho criminal: se lo construye como un desviado de los valores sociales hegemónicos, alejado por completo del «nosotros» en el que los medios se ubican a sí mismos y a su audiencia (y frecuentemente, también a la víctima).

Es así que durante dos días aparecieron, generalmente en recuadros acompañando los datos del caso, la reproducción de las palabras y las expresiones utilizadas por Jonathan en su relato, en las que él utiliza, como vimos, términos propios de los jóvenes de los sectores populares de la Argentina en la actualidad. Muchas veces, estas frases se reproducen aclarando a continuación, o a veces poniendo entre paréntesis, su traducción al lenguaje considerado universal y unívocamente comprendido por todos.

En Clarín, 30 octubre de 2008. Frases de Jonathan: «Acá hay gente que trabaja como en todos lados. Es un barrio normal, pero lo que tiene este barrio es que tenés todo cerca. La droga está acá nomás, tenés una banda (muchos) de fierros (armas)». «Acá hay chorros, drogadictos y malvivientes, pero no hay transa, no venden paco y no hay violines (violadores)». 
Aunque a veces, la traducción estuvo mal hecha: «El joven dijo además, 'a mi careta ${ }^{18}$ me da para pegarle un tiro a un gendarme', haciendo referencia a un estado bajo efectos de estupefacientes» (Blog de Radio Sudamericana 100.5, 30 de octubre de 2008).

Como todo joven, Jonathan efectivamente utiliza vocablos y términos que resultan distintivos de su pertenencia generacional y propios de su medio sociocultural. Sin embargo, la utilización en los medios del recurso de la traducción implica la representación de que se trata de lenguajes (y por lo tanto, de significados y valores morales) completamente extraños y externos entre sí. Se constituye así, al mismo tiempo, al portador de este otro lenguaje como un absoluto extranjero u Otro social. Esta construcción refuerza la concepción de que el hecho fue cometido por alguien que está fuera de «la sociedad», que no comparte sus valores, condensando en esa figura todos los males sociales, y habilitando así respuestas que reclamen la necesidad de sanciones inmediatas y punitivas sobre el desviado, que lo excluya del colectivo social y que permita así reestablecer su normalidad. En sus investigaciones, José Garriga Zucal (2005) explica que este tratamiento resulta propio de los sectores sociales dominantes, que se piensan como universales, piensan el espacio social como homogéneo, y por lo tanto, invisibilizan y estigmatizan de manera violenta las diferencias (Garriga, 2005).

Lo mismo ocurre con la difusión del video presente en el teléfono celular de Jonathan en el que éste aparece manipulando un arma, jugando a apuntar y gatillar al amigo que lo filma y a sí mismo. ${ }^{19}$ Para los periodistas y la audiencia, la actitud de Jonathan en el video resulta inexplicable, muestra de la maldad y la procedencia criminal de éste -y por extensión, de todos los que responden al estereotipo del joven pobre delincuente- y del uso irracional de la violencia que caracteriza a estos jóvenes.

Sin embargo, este video puede entenderse como un acto de presentación de sí mismo, válido en un espacio social en donde el criterio del uso de la fuerza física y la violencia constituye uno de los ordenadores de las relaciones sociales cotidianas. Efectivamente, como vimos al

18 La expresión «careta» remite, por el contrario, a un estado de 'sobriedad' en el que la persona justamente no se encuentra bajo efectos de ningún estimulante.

19 www.taringa.net/posts/info/1705424/Muerte-de-un-gendarme-F_A_html, puede verse parte de este video, donde también aparecen otros videos con extractos de las declaraciones de Jonathan. 
analizar el uso de la categoría de pibes, las transformaciones estructurales sufridas a partir de los ochenta y los noventa en los sectores populares generaron importantes transformaciones en la cultura popular y en las subjetividades de los jóvenes de estos sectores. Entre éstas, la mayor importancia que cobra el uso de la fuerza física y la violencia como criterio ordenador de las relaciones sociales. Y a su vez, el cambio del régimen de significación sobre el cuerpo que ésta implica.

A diferencia de la manera en que se representa la violencia cotidiana entre los sectores medios, en donde ésta aparece como una falla del lazo social, un acto de irracionalidad e incivilización, ${ }^{20}$ el uso de la fuerza física aparece en los sectores populares como una forma propia de sociabilidad, como un recurso valorado y como un criterio de organización que permite identificar, clasificar y jerarquizar a las personas en el espacio social. El manejo de la fuerza física o la violencia supone un capital específico, que permite ocupar una posición valorizada en el mundo social y obtener así reconocimiento social y prestigio, especialmente en aquellos sectores en que esto no se logra a través del uso de otros capitales (económicos o culturales). Históricamente, la valoración de la fuerza física como recurso estuvo asociada a su inserción en los trabajos manuales como fuerza de trabajo, y suponía un régimen de significación corporal en el cual se valoraba la capacidad de sacrificio, de resistencia al dolor. La cultura del aguante, en palabras de los propios actores, estaba ligada a la cultura del trabajo. Sin embargo, con las transformaciones en el mercado de trabajo en los años noventa y la creciente dificultad para invertir este capital a través de la inserción en el trabajo manual, cada vez más el uso de la fuerza física y la violencia solo puede realizarse a través de su inversión como «fuerza de combate» ${ }^{21}$ (Mauger, 2006). Para estos actores sociales, como muestran

20 François Dubet, en sus análisis sobre las violencias urbanas, retoma a Norbert Elías quien desarrolla en sus trabajos sobre «el proceso de civilización» la tesis de que, con el transcurrir de la historia, cada vez más actos se describen como violentos (especialmente los propios de los sectores populares), a la vez que disminuye el nivel de tolerancia sobre lo considerado violento, que aparece como no civilizado. Dubet identifica que este proceso está en la base de la concepción de la violencia actual como un «exceso», sostenida especialmente desde los sectores medios (Dubet, 2008).

21 Como explica Gérard Mauger para el caso de los jóvenes de sectores populares en Francia, ante la falta de capitales de otro tipo (económicos o culturales) que les permitan ocupar una posición valorizada en el 
Garriga Zucal (2005) y también Moreira (2005) en el caso de las hinchadas de fútbol, mostrarse apto en el uso de la violencia y la fuerza física — disposición para el combate o, en palabras de los actores, «tener aguante»— otorga una posición social de prestigio, honor y reputación, y por lo tanto, constituye una forma de afirmación identitaria.

A su vez, como señala Urresti, en los jóvenes de estos sectores la valoración de la fuerza física se combina actualmente con prácticas históricamente ligadas a jóvenes de sectores medios y bohemios en los setenta, propias de la cultura del reviente, ${ }^{22}$ que implicaba otro tipo de significación del cuerpo. Estas prácticas suponían una búsqueda y ampliación de las experiencias corporales en el presente, muchas veces a través de la utilización de drogas, sin importar las consecuencias futuras, y en las que se jugaba con el propio fin (Urresti, 2006:4). En las nuevas generaciones de los sectores populares se puede identificar actualmente la presencia de criterios valorativos propios de ambas culturas (reviente y aguante), combinación que modifica la significación corporal propia de estos sectores.

La peculiaridad de lo que ocurre en el conurbano bonaerense en donde se encuentra el barrio en el que vive Jonathan es que allí, a me-

mundo social, los jóvenes priorizan el criterio de jerarquización en el que pueden ocupar una posición menos subordinada: la valoración del capital físico. En una época de expansión del trabajo industrial, esto caracterizará a los jóvenes obreros que utilizaron la «fuerza física» como «fuerza de trabajo», pero también a aquellos jóvenes con estilos de vida considerados desviados que utilizaron la fuerza física como «fuerza de combate». En un contexto como el actual de desestructuración del mundo obrero industrial y sus valores, las prácticas relacionadas con este principio de jerarquización se expanden cada vez más en términos de valorización del uso de la violencia física como manifestación del «capital guerrero» o «fuerza de combate» (Mauger, 2006).

22 Marcelo Urresti explica en sus trabajos que «la cultura del reviente es una cultura que históricamente se correspondió con el estilo de vida de los bohemios y de los artistas de clase media y media alta. El reviente en los años sesenta y setenta implicaba entre otras cosas la búsqueda de una experiencia ampliada del cuerpo y de sus percepciones [...] En esa búsqueda de los límites la droga cumplía un papel fundamental. Era una droga que implicaba el puro goce hedonista, sensual, que obviamente descontrolado es capaz de llevar a la muerte. El reviente era el límite tanático de la erótica o, invirtiéndolo, el eros que se presenta en el juego con el propio fin» (Urresti, 2006:4). 
diados de los noventa, se produjo como novedad la incorporación y circulación de drogas duras y armas en los sectores populares. Estos elementos se sumaron entonces a esta trama de relaciones y significados organizados alrededor del uso de la fuerza física y la violencia, al mismo tiempo que introdujeron nuevas posibilidades que operaron en la transformación de estas mismas relaciones y sentidos.

El video en el teléfono celular de Jonathan, ahora, cobra un sentido distinto al otorgado por los medios de comunicación: la presentación de sí como alguien violento, capaz de utilizar un arma, se entiende como una actitud valorada propia de la cultura del aguante, como disposición a la pelea; pero al mismo tiempo, jugando con el revólver a apuntar y gatillar a su amigo y a sí mismo, aparece un juego con el límite del propio cuerpo y del cuerpo del otro, en una actitud que cobra sentido como parte de la cultura del reviente, también presente en los jóvenes de los sectores populares en la actualidad.

\section{8. «EL GENDARME». CONSTRUCCIÓN DE CERCANÍA CON LA VÍCTIMA V/S LA RELACIÓN DE LOS JÓVENES CON LAS FUERZAS DE SEGURIDAD}

Para terminar, así como nos detuvimos en la construcción de la figura del victimario, resulta interesante analizar la manera en que desde los medios se produce la figura de la víctima. Veamos como ejemplo lo publicado en el diario La Nación el 30 de octubre de 2008.

\footnotetext{
CONMOCIÓN Y TRISTEZA EN LA DESPEDIDA DEL GENDARME ASESINADO Varios centenares de personas y efectivos acompañaron los restos de Roberto Omar Centeno, quien recibió sepultura esta tarde
}

Córdoba. Varios centenares de conmovidas personas y gendarmes acompañaron los restos de Roberto Omar Centeno hasta el Cementerio de Jesús María, donde esta tarde recibieron sepultura.

Durante el velatorio y la ceremonia fúnebre, la familia recibió innumerables muestras de solidaridad. La esposa, Irene de Centeno, la madre y los hermanos encabezaron la marcha hasta el Panteón de Gendarmería Nacional.

Una de las hermanas llevaba en sus brazos al pequeño hijo, de apenas algo más de un mes de vida, que el cabo no llegó a conocer. Era padre de dos pequeños.

Efectivos del arma escoltaron el féretro y le tributaron honores en la despedida final. No hubo discursos ni declaraciones de los familiares. Pero no dejo de ser un dato altamente significativo que del cortejo formaron parte más de un millar de gendarmes y un número similar de civiles. 
Como se percibe en la nota, cuando se trata de reconstruir la figura de la víctima, por el contrario de lo que ocurre con la del victimario en la que se utilizan recursos enunciativos que resaltan la distancia (como la traducción), los medios dan cuenta de una cercanía social, moral, y hasta afectiva, que propicia la identificación con su figura. Esta narrativa produce un efecto particular: «la construcción conmiserativa de la víctima no hace sino acrecentar el peso de la culpa y del culpable» (Arfuch, 1997:28). Para ello se utilizan una serie de recursos particulares. Uno de ellos es la construcción de un nosotros que incluye a la audiencia y a la víctima como parte de un mismo grupo social. Para ello se da cuenta de toda manifestación de afecto y solidaridad, lo que genera la idea de que se trataba de alguien popular, familiar y querido. Otro recurso es la mención de la cantidad de personas («civiles») que fueron al velorio, que se utiliza también como un indicador de su valor social y de su «representatividad». Otro recurso es la búsqueda y reproducción de los relatos de sus compañeros y familiares que dan cuenta de sus virtudes, en tanto testigos de la calidad humana de la víctima.

Es interesante observar que se utiliza también el apelativo de «joven» para dar cuenta de la identidad de la víctima, que tenía veintiocho años. De esta manera, se construye discursivamente la existencia de jóvenes buenos — el que dio su vida por el cuidado de los demásy jóvenes malos —el autor del crimen, y también Jonathan-, como una manera de reforzar la idea de maldad individual (o bondad individual) producto de una elección.

Otro de los mecanismos es la representación de la víctima como la encarnación ejemplar de ciertos valores sociales y morales, siendo el tratamiento de la noticia una ocasión para confirmarlos/afirmarlos, y resaltando por oposición lo horroroso del crimen y la amenaza que su autor constituye para el conjunto de la sociedad. Es así como todos los medios mencionan los datos de la vida familiar del gendarme, repitiendo el hecho de que era un padre de dos niños pequeños (que encarna el valor de la familia y del buen padre) y se enfatiza que «no llegó a conocer» o en palabras de otro medio, que «dejó dos huérfanos», lo que aumenta la percepción de la maldad de quien cometió el acto. Por el contrario, del supuesto autor o de su equivalente en el relato (Jonathan) no se mencionan sus relaciones familiares ni su trayectoria de vida. En la mayor parte de los medios, el hecho de que sea un militar aumenta este recurso de la encarnación de los valores sociales y morales compartidos, identificándolo simbólicamente con los valores de la patria, y por lo tanto, proponiendo a esta institución como modelo de estos valores. Con 
el correr de los días, la figura del gendarme fue tomando protagonismo hasta ser equiparada a la figura de un héroe, casi como un caído en combate, lo que queda de manifiesto cuando se reproducen palabras del por entonces Ministro de Justicia, Seguridad y Derechos Humanos de la Nación refiriéndose al gendarme de manera casi familiar, y resaltando la indignación que le produce el hecho:

El ministro de Justicia, Seguridad y Derechos Humanos, Aníbal Fernández, se manifestó indignado por el hecho. 'Estoy absolutamente consternado y con una bronca fenomenal porque un pibe de veintiocho años, haciendo un parte adentro de la caseta, recibió un balazo en la oreja y le salió por la cara, lo mataron impunemente, ni siquiera fue un enfrentamiento', dijo el ministro (Reproducido en La Nación y en Clarín el 31 de octubre de 2008).

Sin embargo, la pertenencia a las fuerzas de seguridad está lejos de representar la encarnación de los valores del colectivo o la legitimidad de la ley entre los jóvenes de los sectores populares en la Argentina. Las investigaciones dan cuenta de que para estos jóvenes las fuerzas de seguridad (y en particular, la policía) constituyen una banda rival a la que oponerse. Para estos jóvenes «la policía tiene poco que ver con la ley, es una banda más, mejor armada y más potente. A lo sumo, aparece como socia y protectora de la 'alta delincuencia'» (Kessler, 2004:126). ${ }^{23}$ Kessler da cuenta cómo la relación conflictiva entre los jóvenes y la policía se basa en una experiencia de una continua persecución sin motivación aparente, en la que no está exenta la amenaza de la muerte potencial, en algunos casos directamente explicitada, lo que refuerza la representación de que constituyen un enemigo mortal y lleva a actuar en consecuencia.

En el caso de los jóvenes de «Fuerte Apache» se suma a la relación con la policía la relación con la Gendarmería, que fue consignada en las puertas del barrio como mecanismo de refuerzo del control y la seguridad. La Gendarmería es en parte percibida por los vecinos en general como una posibilidad de controlar también las arbitrariedades de la policía, o al menos su inoperancia, en el espacio público del barrio, $\mathrm{y}$ en este sentido es valorada positivamente $-\mathrm{y}$ es por eso que

23 Muchos estudios llegaron a conclusiones similares en sus estudios sobre los «pibes chorros» (Isla, 2002) (Miguez, 2002), sobre los «chicos de la calle» (Gentile, 2006 y 2009) y sobre el caso particular de los hinchas de fútbol y su relación con la policía (Alabarces, Cohelo y otros, 2000). 
Jonathan manifiesta que «estamos más tranquilos con la gendarmería»- Sin embargo, en el caso particular de los jóvenes del barrio, la experiencia de la relación es la del hostigamiento permanente, ya que sufren malos tratos y violencia física (golpizas, patadas), y una persecución discriminatoria constante dentro del propio barrio por la manera en que se visten, por tener tatuajes, etcétera.

En este contexto cobran otro sentido los dichos de Jonathan: «No sé si los que lo mataron estaban drogados, porque a mí de careta también me da para meterle un tiro a un gendarme por las veces que me cagaron a palos» (Clarín, 30 de octubre de 2008).

\section{Palabras finales}

El estereotipo del joven pobre y delincuente es una figura central en la representación de la violencia urbana en la actualidad. Esta figura mediática condensa tres problemáticas diferentes entre sí: la inseguridad, la violencia en los jóvenes y el delito, que constituyen fenómenos distintos, con causas diferentes y que requieren intervenciones particulares sobre cada uno de ellos. Sin embargo, producto de este efecto de condensación, muchas veces se pretende, a través del debate sobre el tratamiento de este personaje social, resolver las tres problemáticas.

Sólo para evidenciar estas diferencias: si la cantidad de muertes violentas constituye un indicador de los niveles de la inseguridad física en una sociedad, en la Argentina ocurren más muertes violentas por accidentes de tránsito (no delito) que por homicidios (delito). ${ }^{24}$ Dicho de otra manera, los accidentes de tránsito son la principal causa de inseguridad. Por otro lado, respecto de los delitos, los hay de todo tipo, y no necesariamente todos recurren a la violencia física para su concreción. Podríamos incluso deducir que aquéllos a los que más personas afectan no utilizan la violencia corporal para su realización, recurso siempre de los que no tienen otros recursos. Se trata por el contrario de los grandes casos de corrupción, estafas públicas y privadas, especulaciones financieras, explotación laboral, etcétera. Por último, el tema de la violencia y los jóvenes no puede analizarse sin tener en cuenta los cambios en las prácticas y significaciones que se operaron en las nuevas generaciones, producto de las transformaciones en el mercado laboral y sus consecuencias en la estructura social, que

24 Tal como lo muestra Pablo Bonaldi en su artículo sobre las muertes violentas en la Argentina (Bonaldi, 2002). 
modificaron las formas tradicionales de socialización y el lugar que este grupo ocupa en el conjunto social. De la misma manera que resulta indispensable tener en cuenta también el tipo de vínculo establecido entre los jóvenes y las fuerzas de seguridad, cuya conflictividad constituye un rasgo identitario generacional en la Argentina actual (Svampa, 2005:178). En palabras de Pablo Bonaldi, «los jóvenes no están hechos de un material distinto del resto de la sociedad. Sus actitudes y comportamientos sólo se vuelven comprensibles cuando se logra inscribirlos en los sistemas de relaciones que caracterizan a la sociedad en su conjunto» (Bonaldi, 2002:289).

El análisis del «caso Jonathan» nos permitió poner de manifiesto las imágenes propuestas, las formas de construcción de las narraciones y los procedimientos enunciativos utilizados a través de los cuales se configura este estereotipo social en los medios de comunicación. A su vez, este «caso» nos permite conocer algunas de las reacciones sociales suscitadas por este tipo de tratamiento mediático. En el plano del debate público, la inscripción de este caso en la «serie» de delitos cometidos por jóvenes o «menores» abonó la idea de la necesidad de una baja en la edad de imputabilidad penal, lo que generó declaraciones públicas de políticos y gobernantes y llegó hasta la presentación de un proyecto de ley por parte del gobernador de la Provincia de Buenos Aires. En el plano de las interacciones cotidianas en el barrio, la exposición de Jonathan en todos los medios a lo largo de los días, y de sus declaraciones en donde se publicitaron ciertos códigos y arreglos vigentes en el barrio, propios del entramado entre la policía, la Gendarmería, los punteros políticos, las bandas delictivas de los antiguos y la relación con el resto de los pibes chorros, tuvieron como consecuencia un ensañamiento particular con su persona. Tanto por parte de las propias fuerzas de seguridad («era un bocón», dijo un miembro de la Gendarmería a Página 12 el 30 de octubre, mientras que la policía lo mantuvo encarcelado durante cinco días, en los que recibió fuertes golpizas ${ }^{25}$ ), como por el hecho de que, al ser el primer detenido por el tema y alcanzar tal grado de notoriedad, todo el despliegue policial posterior fue visto por algunos actores del barrio como consecuencia de lo que Jonathan pudo haber contado mientras estaba

25 La aparición mediática de Jonathan tuvo también como efecto mi reconexión con su familia, luego de dos años de haber dejado de concurrir a su barrio por trabajo de campo, para ofrecer ayuda y acompañamiento legal durante los días en que estuvo detenido. 
arrestado. Esto llevó a que la madre de Jonathan recibiera amenazas y rumores acerca de las represalias que podía sufrir, lo que lo llevó a tomar la decisión de abandonar el barrio inmediatamente después de salir de la comisaría, y que hasta ahora nunca más haya regresado.

Hemos llegado hasta aquí no precisamente para oficiar una desmentida acerca de lo relatado en los medios de comunicación, sino para dar cuenta del carácter de constructo social de aquello que aparece en los debates públicos como completamente naturalizado: la relación entre juventud, pobreza, delito y violencia. Productores al mismo tiempo que reproductores del debate social actual, los medios masivos de comunicación tienen un rol destacado en la configuración de los ejes sobre los que se articulan las figuras de lo amenazante y los sentimientos que ellas despiertan; y por ende, una importante responsabilidad. Sin embargo, los estudios muestran que, al menos en la Argentina, en ellos existe una escasa reflexión sobre su propio rol en la generación de estos sentimientos; por el contrario, se perciben a sí mismos como el reflejo de «lo que pasa». ${ }^{26}$ Pero es justamente al calor de la explotación mediática de esta figura que se producen, como analizamos, determinadas reacciones sociales y políticas en las que se reclama o propone la toma de medidas con carácter de urgente y se dirime el tratamiento social de la cuestión juvenil.

BuEnOS Aires (ARGENTINA), ENERO 2011

RECIBIDO: ENERO 2011

ACEPTADO: MARZO 2011

\section{REFERENCIAS BIBLIOGRÁFICAS}

26 Tema al que se refiere Kessler en su estudio sobre el sentimiento de inseguridad (Kessler, 2007:99). 
Alabarces, P.; R. Coelho et al. (2000): «'Aguante’ y represión. Fútbol, violencia y política en la Argentina». P. ALABARCES (compilador): $P e$ ligro de gol. Estudios sobre deporte y sociedad en América Latina. Buenos Aires: CLACSO/ASDI.

ARfuCH, L. (1997): Crímenes y pecados de los jóvenes en la crónica policial. Buenos Aires: UnICEF.

BONALDI, P. (2002): «Evolución de las muertes violentas en la Argentina, 1980-1999». S. GAYOL y G. KESSLER (compiladores): Violencias, delitos y justicias en la Argentina. Buenos Aires: Manantial y UNGS.

DGE: (2007): «Informe de prensa de la encuesta socioeconómica del barrio Ejército de los Andes». Buenos Aires: DGE.

DUBET, F. (2008): «Seminario sobre violencias urbanas». Buenos Aires, CFA/UBA.

GARRIGA ZUCAL, J. (2005): «Pibitos chorros, fumancheros y co aguante. El delito, las drogas y la violencia como mecanismos constructores de identidad en una hinchada del fútbol». P. ALABARCES (organizador): Hinchadas. Buenos Aires: Prometeo.

GENTILE, M. F. (2009): «En el CAINA te habla la boca. La interacción cotidiana en un centro de atención para niños y adolescentes en situación de calle, desde la experiencia de los chicos que la frecuentan». M. CHAVES y otros (coordinadores): Estudios en juventudes en Argentina I. Hacia un estado del arte 2007. La Plata: RENIJA y Editorial Universidad Nacional de la Plata.

- (2006): «La experiencia de la vida en la calle en los niños y jóvenes de una institución de asistencia en Buenos Aires». Tesis para la optar al grado de máster en sociología, Centre d’Études des Mouvements Sociaux, École des Hautes Études en Sciences Sociales, París (inédita).

IsLA, A. (2002): «Los malvivientes». S. GAYOL y G. KESSLER (compiladores): Violencias, delitos y justicias en la Argentina. Buenos Aires: Manantial y UNGS.

KAMINSKY, G.; G. Kessler y D. KosovsKy (2007): El delito en la Argentina post-crisis. Aportes para la comprensión de las estadísticas públicas y el desarrollo institucional. Buenos Aires: Friedrich Ebert Stiftung, UNLA, INECIP, ILANUD.

Kessler, P. (2004): Sociología del delito amateur. Buenos Aires: Paidós.

- (2002): «Entre fronteras desvanecidas. Lógicas de articulación de actividades legales e ilegales en los jóvenes». S. GAYOL y G. KESSLER (compiladores): Violencias, delitos y justicias en la Argentina. Buenos Aires: Manantial y UNGS.

MAUGER, G. (2006): Les bandes, le milieu et la bohème populaire. Études de sociologie de la déviance des jeunes des classes populaires (19752005). París: Belin.

MigueZ, D. (2002): «Rostros del desorden. Fragmentación social y la nueva cultura delictiva en sectores juveniles». S. GAYOL y G. KESSLER (com- 
piladores): Violencias, delitos y justicias en la Argentina. Buenos Aires: Manantial y UNGS.

MoreirA, M.V. (2005): «Trofeos de guerra y hombres de honor». P. ALABARCES (organizador): Hinchadas. Buenos Aires: Prometeo.

SABSAY, L. (1997): «Representaciones de los jóvenes en la prensa o la puesta en escena del 'estado de las cosas'». L. ARfuch: (1997): Crímenes y pecados de los jóvenes en la crónica policial. Buenos Aires: UNICEF.

SVAMPA, M. (2005): La sociedad excluyente. La Argentina bajo el signo del neoliberalismo . Buenos Aires: Prometeo.

TONKONOFF, S. (2007): «Tres movimientos para explicar por qué los pibes chorros visten ropas deportivas». VV.AA.: La sociología ahora. Buenos Aires: Siglo XXI.

URresti, M. (2008): «Seminario sobre violencias urbanas». Buenos Aires: CFA/UBA.

— (2006): «Jóvenes excluidos totales. El cuerpo ‘propio’ como última frontera». Exposición en las «Segundas jornadas sobre problemáticas juveniles: violencia-lenguaje y políticas públicas». Instituto del Paraná, Rosario. 